\title{
Characterization of the virE operon of the Agrobacterium Ti plasmid pTiA6
}

Stephen C.Winans, Paul Allenza*, Scott E.Stachel, Kevin E.McBride ${ }^{1}$ and Eugene W.Nester

Department of Microbiology and Immunology, University of Washington, Seattle, WA 98195 and

${ }^{1}$ Calgene, 1920 Fifth Street, Davis, CA 95616, USA

Received August 26, 1986; Revised and Accepted December 16, 1986

ABSTRACT

The Agrobacterium tumefaciens $T i$ plasmid contains at least six transcriptional units (designated vir loci) which are essential for efficient crown gall tumorigenesis. Mutations in one of these loci, virE, result in a sharply attenuated virulence phenotype. In the present communication, we have analyzed the virE operon at the molecular level. This locus contains open reading frames coding for two hydrophilic proteins having molecular weights of approximately 7,000 daltons and 60,500 daltons. Using a maxice11 strain of E. coli, we have visualized two proteins encoded by virE which correspond in size to these open reading frames. Analysis of codon usage of

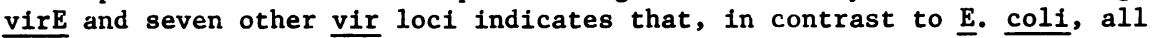
possible codons for a given amino acid are utilized at approximately the same frequency.

\section{INTRODUCTION}

The pathogenic bacterium Agrobacterium tumefaciens genetically transforms infected plant cells by introducing a defined segment of plasmid-coded DNA (the T-DNA) into the plant cell nucleus where it becomes covalently integrated intc genomic DNA and directs the synthesis of mitogenic phytohormones (1). In addition to the T-DNA, two chromosomal loci and six plasmid loci have previously been identified by means of transposon mutagenesis which are essential for virulence, and these loci are thought to be required for the transfer and integration of the T-DNA (2-5). The six plasmid-coded vir loci reside within a 35 kilobase region of the $\mathrm{T} 1$ plasmid. Mutations in virA, virB, virD, or virG completely abolish virulence, while mutations in

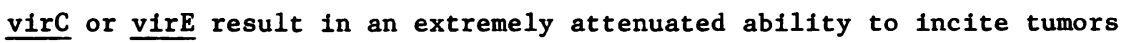
(6-7).

The infection process must be comprised of a number of sequential events. Once the bacterium senses the proximity of a wounded plant susceptible to infection, it must 1 ) activate the synthesis of proteins required for infection, 1i) initiate cell-cell contact, 1ii) process the T-DNA into a form capable of transfer, and iv) direct T-DNA transfer and integration into 
the plant genome. The role of vir gene products in these events is being studied intensively in a number of laboratcries. The products of the virA and virG loci have recently been shown to be required for the transcriptional induction of the vir genes and are homologous to other positive regulatory proteins (8-9). A $3.6 \mathrm{~kb}$ region of DNA containing the first two genes of the virD operon, when expressed in E. coll, is sufficient to catalyze the deletion of DNA lying between the left and right T-DNA border sequences (10). The first two genes in virD are also sufficient to cause single strand cleavage of border sequence DNA in both Agrobacterium and $\underline{E}$. coli (11). The roles of other vir products in tumorigenesis are unknown.

The virE locus is of particular interest in that strains containing virE mutations can be complemented during mixed infections using a "helper" strain of Agrobacterium (12; Corbin and Nester, unpublished observations). The helper strain must express not only virE but also virA, virB, virD and virG. This complementation suggests that the virE product synthesized in one bacterium may be utilized during infection by a second strain. Therefore either the virE product itself or a secondary metabolite made by it may be localized extracellularly. Recent evidence has been interpreted as suggesting that virE may play a role in the covalent integration of the T-DNA into the plant genome (13).

The present study extends our analysis of the virE locus to the molecular level. The nucleotide sequence of a $2.4 \mathrm{~kb}$ region which is required for

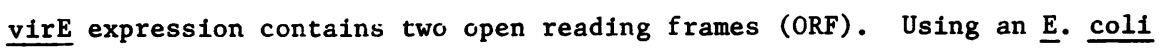
maxicell strain, we have visualized two proteins which correspond in size to these two ORFs. The smaller, upstream CRF has been designated virEl while the longer, downstream ORF has been designated virE2.

\section{MATERIALS AND METHODS}

\section{Materials}

Restriction endonucleases were purchased from BRL or New England Biolabs and used according to the supplier's recommendations. DNA polymerase I, Klenow fragment, was purchased from Boehringer Mannheim or BRL; SI nuclease from New England Biolabs, and E. coli exonuclease III and T4 ligase from BRL. The M13 sequencing primer, unlabelled nucleotides, and dideoxynucleotides were obtained from P-L Biochemicals. The Cyclone kit was purchased from IBI. ${ }^{35} \mathrm{~S}$ labelled dATP was purchased from New England Nuclear.

\section{Strains and Plasmids}

Plasmid DNA was isolated by the method of Birnboim and Doly (14). Plasmid pSW108 is a derivative of pUC7 containing a $3.2 \mathrm{~kb}$ XhoI fragment 
containing virE cloned into the SalI site of the vector. Plasmids pSW153 and pSW154 were constructed by cloning the SphI-BamHI fragment (utilizing a BamHI site derived from the pUC7 polylinker) and the SphI-SmaI fragment of pSW108 indicated in Fig. 1, respectively, into pUC19 which had been cut with SphI and either BamHI or SmaI.

DNA sequencing

DNA sequencing was performed by the chain termination method (15) using ${ }^{32} \mathrm{P}$ and ${ }^{35} \mathrm{~S}$ labelled deoxynucleotides (16). Progressive deletions of $\mathrm{M} 13$ clones containing SalI fragment 21 in either orientation were created by methods described by Guo and Wu (17) and by Dale et al. (18). Both strands of DNA were sequenced. The 0.3 kilobase SalI fragment shown in Fig. 1 was cloned into Ml3mpl9 in both orientations and sequenced along its entire length.

Protein analysis

Plasmid-encoded proteins were radiolabelled with ${ }^{35}$ S-methionine using the maxicell technique of Sancar et al. (19). The virE2 product was visualized using $10 \%$ polyacrylamide gels as describe by Laemli (20). The virEl product was visualized on $15 \%$ polyacrylamide gels using a phosphate-urea buffer system as described by BRL (21). Whole cell proteins were visualized using Coomassie Brilliant Blue G, in $10 \%$ methanol and $10 \%$ glacial acetic acid.

RESULTS

Nucleotide Sequencing of virE

The virE operon was localized to a $2.2 \mathrm{~kb}$ region at the right end of the vir region (5), using the genetically engineered transposon Tn 3 HoHol (22). These insertions are shown in Fig. 1. The left end of virE lies between insertion $\Omega 362:: \operatorname{Tn} \underline{3} H \circ H o l$, (which is $\mathrm{Vir}^{+}$) and $\Omega 361:: \operatorname{Tn} \underline{3}$ HoHol, (which is $\left.\mathrm{Vir}^{-}\right)$(5). Similarly, the right end of the gene lies between insertion 507::Tn 3 HoHol $\left(\mathrm{Vir}^{-}\right)$and $\Omega 534:: \mathrm{Tn} 3 \mathrm{H}$ Hol $\left(\mathrm{Vir}^{+}\right)$. Furthermore, the cosmid pVK223, which contains approximately $25 \mathrm{~kb}$ of $\mathrm{Ti}$ plasmid DNA inclusive and to the left of SalI-21, does not complement virE mutations, indicating that DNA to the right of SalI-21 must also be required. These data indicate that virE must lie wholly to the right of the leftmost SalI site and to the left of the rightmost SalI site shown in Fig. 1. pSW108, which contains this region, does contain all sequences necessary to complement mutations in virE (data not shown). Tn 3 HoHol contains a promoterless $\underline{1 a c}$ operon and therefore creates transcriptional and translational fusions between genes into which it 


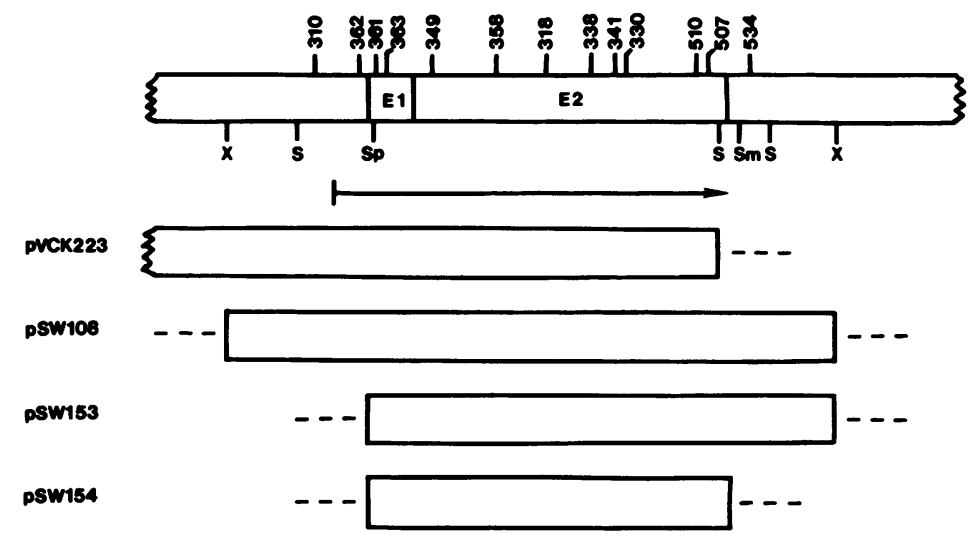

Figure 1: Physical map of the virE operon. Insertions of Tn 3 HoHol are shown as vertical lines at top. Insertions 310,362 , and 534 are vîr ${ }^{+}$while all other insertions are vir . The direction of transcription is indicated by an arrow beneath the physical map. Restriction endonuclease cleavage sites are indicated by capital letters under the first line. S indicates SalI sites, X: XhoI, Sm: SmaI, Sp: SphI. Clones of virE DNA on plasmid vectors are described in Materials and Methods.

has transposed and $\beta$-galactosidase (22). This feature of the transposon has been used to show that the transcription of virE is inducible by cocultivation with plant cells and that the locus is transcribed left to right as drawn in Fig. 1 (5).

Fig. 2 shows the nucleotide sequence of this region. There are two ORF's which fall within the virE region defined above. The first ORF (virE1) codes for a 65 amino acid protein having a molecular weight of 7132 daltons and a net charge of -4 . The second $O R F$ (virE2) codes for a 533 amino acid protein having a molecular weight of 60518 daltons and a net charge of -3 . Both ORF's are preceded by sequences similar to the Shine and Dalgarno sequence (TAAGGAGGTG, ref. 23) which precedes many inftiation codons in E. coli (these sequences are indicated by overlines in Fig. 2). Only four bases separate the termination codon of the small ORF and the initiation codon of the large $O R F$, suggesting that they may be translationally coupled. The virE transcription initiation site, as localized using S1 mapping (24), is at base 199 (shown in a black box in Fig. 2), indicating that the virE operon contains a considerable (188 bp) untranslated region of DNA upstream of the first ORF. There is a region of almost perfect dyad symmetery (22 out of 23 bp) between bases 135 and 157 (TTGAAACGCGATATCCGTTTCAA). Since this sequence is directly upstream from the putative -35 region (CCGAGT at bases 161-166, 
GTCGACCGGCTGCTCGTCACCAACAATGCTCACAGGGATACGATGGCCTCGACAGTCAGGCCGCGTGCGTCCAGTCTTTCCAGTTCCTCC CTTTCAGGTCGATTGTGGCATCATTTATTGCCTGCTCATTGCAGTTGAAACGCGATATCCGTTTCAAGACCCGAGTATGGATGGTACTTT GGAGATATGAGCAC ПTGCCAGACTTCCCGGTCGgAGACTTAAAAATTCCGATAAGAGGTTACTGACGACGGACCTTATAAGTGGGTCGTC TAGTGGTCGCACTGATCAAAACAGTTCCGCCCCCGGCTTTGCTCAAAGTAGCAAAGCAGCTTTATCTCGGGTTGCAGAGGATTTTCTGGA

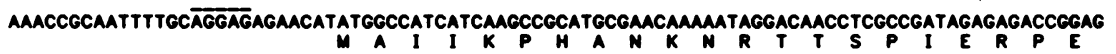

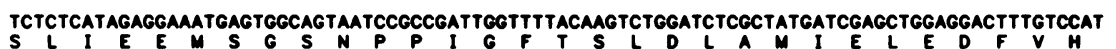
CGgTGCCCGCTCCCAGGAGACAATCTTGCTGGTCAGĀAGGAGTGAGACGATGGATCTTTCTGGCAATGAGAMATCCAGGCCTTGGAGGA

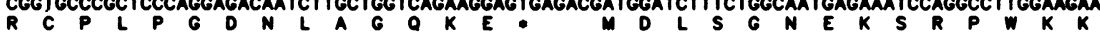

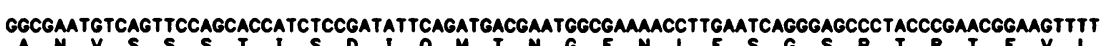
$A N V$ S S S T I S D I Q M T N G E N L E S G S P T R T E V L

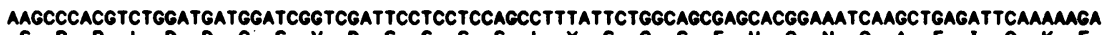
S P R L D D G S V D S S S S L Y S G S E H G N OA E I Q K E GCTGTCCGCCTTGTTCTCGAACATGTCTTTGCCAGGCAACGATCGGCGCCCGGACGAATACATTCTCGTGCGTCAAACGgGACAAGATGC L S A L F S N M S L P G N D R R P D E Y I L V R O T G Q

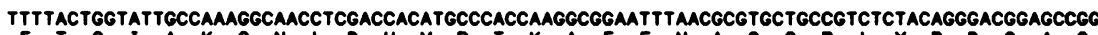
F T G I A K G N L D H M P T K A E F N A C C R L Y R D G A G

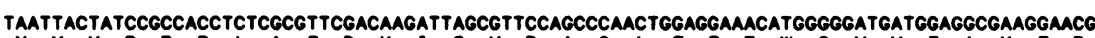

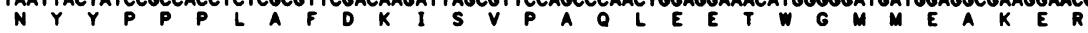
taAcaAactacggttTcagtacangttggacgtatggatcatgcgcacgctgatatggggatcactggcacagagatctittatcaaac

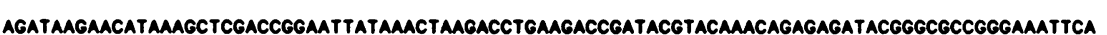
D K N I K L D R N Y K L R P E D R Y V Q T E R Y G R R E I Q AAAGCGATATCAGCACGAACTCCAGgCTGGTTCGCTGCTGCCCGATATTATGATCAAAACTCCCAAAAATGACATCCACTTCGTGTACAG K R Y O H E L O A G S L L P D I M I K T P K N D I H F V Y R GTTTGCCGgCGACAATTACGCCAACAAACAATTCAGCGAGTTTGAACACACCGTCAAGCGCAGgTATGgCGgCGAGACTGAGATCAAATT F A G D N Y A N K G F S E F E H T V K R R Y G G E T E I K L GAAGTCAAAGTCAGGCATTATGCATGACTCGAAATATCTGGAATCCTGGGAACGGGGCAGTGCGGATATTCGCTTCGCGGAATTTGTTGG K S $S$ K S S G I M H D S K Y Y L E S W E R G S A CGAAAATAGAGCTCACAATCGGCAGTTTCCAACTGCGACCGTAAATATGgGaCAGCAGCCAGACGgGCAGgGCGGTTTGACCCGCGACCE E N R A H N R Q F P T A T V N M G Q Q P O G G Q G G $L$ T R D R TCATGTGAGCGTTGAATTCCTAATGCAAAGCGCACCGAATTGCCCTTGGGCGCAAGCTTTGAAAAAGGGAGAACTGTGGGATCGCGTTCA H V S V E F L M Q S A P N C P W A Q A L K K G E L W D R V Q GTTGCTTGCTCGCGACGGCAACCGCTATCTGTCGCCTCACAGATTAGAATATTCTGACCCTGAACATTTCACCGAGTTGATGAACCGGGT L L A R D G N R Y L S P H R L E Y S D P E H F T E L M N R V TGGTTTGCCCGCATCGATGGGTCGGCAAAGCCATGCGGCTAGTATCAAATTCGAAAAGTTTGACGCGCAGGCAGCGGTTATTGTCATAAA TGGCCCGGAGTTCCGTGACATCCATGACTTGTCTCCTGAAACCTGCAAAATGTGTCCACCAaAGATGTCATCGTCGCCGATCGCAATGA G P E L R D I H D L S P E N L Q N V V S T K D V I V A D R N E GAATGGTCAGAGAACTGGCACGTACACCAGCGTCGCGGATATGAGCGCTTGCAGTTAAGGCTGCCAGCCGATGCAGCGGGGGTGCTTGG

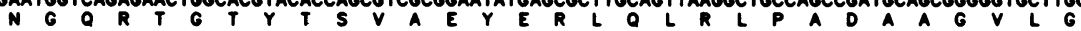

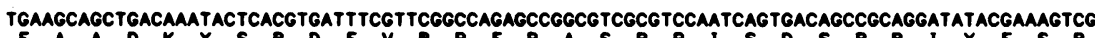
E A A D K Y S R O F V R P E P A S R P I S D S R R I Y E S R ACCGCGTAGCCAMAGCGTCAACAGCTTTTGACGTTCCTTCTGCCGCGTCAATGAGGAAGCTCGTTGACCCGGGTTTGCCAATGAĀGEGC $P R S O S V N S F$

TCAATCATGgTGAGCACTACGAAGAAAAGTTTTGCAAAGTCECTGACGgCAGATATGCGCCGTTCTGCTCAGCGCGTTGTCGAGCAAATG

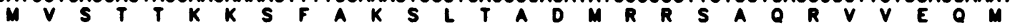
CGAAAAGCATTGATTACCGAAGAMGAGGCGCTCAAGCGGCAMACCAGACTGGAGAGCCCCGATAGgAAGCGAAAGTATGCTGCTGATATG 2430 $R K K A L I$ T E E E A L K R O T R L E S P D R K R K Y A A D M GCGATAGTCGAC

Figure 2: Nucleotide sequence of a $2.442 \mathrm{~kb}$ interval containing the virE operon. virEl extends from nucleotide 388 to 583, virE2 extends from nucleotide 590 to 2190, and a hypothetical ORF extends from nucleotide 2257 to the end of the sequence. The transcription inftiation site at bp 199 is shown in a black box, while lines drawn over the DNA sequence indicate putative ribosome binding sites upstream of each initiation codon. 
ref. 24), it could conceiveably play some role in the transcriptional induction which occurs during cocultivation with plant suspension cells (25), although other vir promoters which are coordinately regulated with virE do not contain regions of dyad symmetry. All sequences necessary for regulation

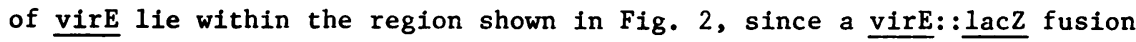
containing only these sequences is fully regulated by the virA and virG regulatory system (8-9).

Fig. 2 also shows the $5^{\prime}$ portion of a third ORF which lies to the right of the virE operon. It seems possible that this ORF encodes a functional gene, since it is preceded by sequences similar to the -10 and -35 sequences of many E. coli promotors (the sequences TTGAC at bp 2188-2192 and AAT at bp 2211-2213) and is also preceded by a sequerce similar to many E. coli ribosome binding sites (the sequence AAGG at bp 2245-2248). Insertions in this ORF do not cause avirulence on Kalanchoe leaves; therefore, if it does encode a functional gene, then its product is not essential for tumorigenesis.

The observation that virE mutants can be complemented transcellularly suggests that virE may code for a product which is exported from the bacterium. If this is true, then one might predict that one or both proteins may

\section{HYDROPHILICITY AWHLYSIS}

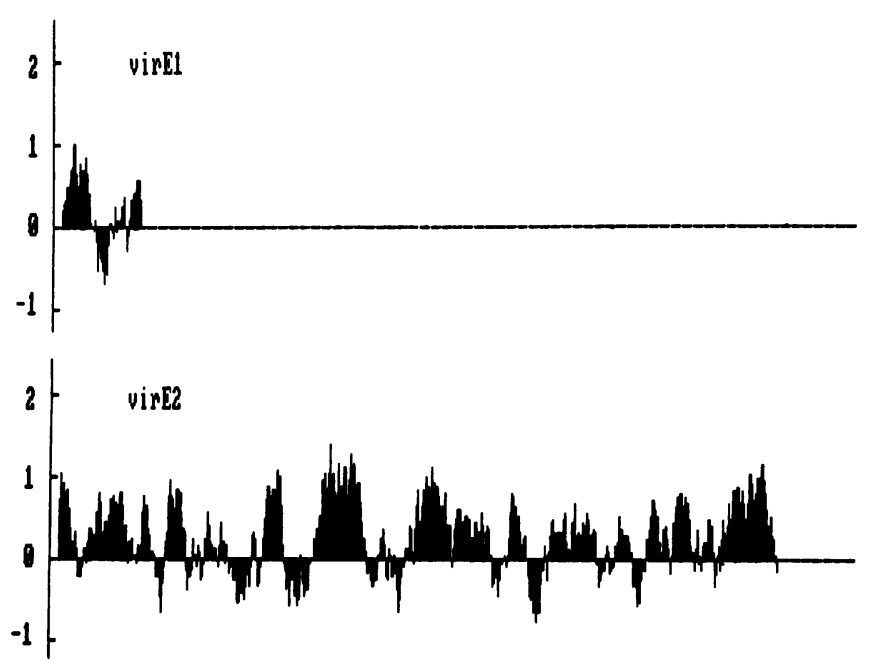

Figure 3: Hydrophilicity plots of VirEl and VirE2. The PROTANA algorithm of Champoux was used with a scan length of 15 . Line segments above the horizontal axis indicate hydrophilic portions of the protein, while line segments below the axis indicate hydrophobic regions. 
contain a sequence of hydrophobic amino acids common to many secreted proteins. Fig. 3 shows the distribution of hydrophilic and hydrophobic amino acid residues of the two proteins, using an algorithm developed by Hopp and Wood (26) and modified by J. Champoux. Both proteins are composed largely of hydrophilic amino acid residues and do not contain any hydrophobic regions expected of a secreted or membrane-associated protein (27). If one or both proteins are exported, then secretion must not rely upon signal peptides. Visualization of virE proteins

We have visualized polypeptides corresponding in size to both virEl and virE2 by radiolabelling plasmid encoded proteins with ${ }^{35} \mathrm{~S}$-methionine using an E. coli maxicell strain. The plasmid used in this study, pSW108, is a derivative of pUC7 containing an $3.2 \mathrm{~kb}$ XhoI fragment inserted into the SalI site of the vector (Fig. 1). Fig. $4 \mathrm{a}$ and $4 \mathrm{~b}$ show that pSW108 encodes two proteins having apparent molecular weights of 7,000 and 66,000 daltons. The mobility of VirEl corresponds well with the molecular weight of the protein deduced from the DNA sequence. In contrast, the apparent molecular weight of VirE2 protein is about $10 \%$ greater than that deduced from the DNA sequence. This discrepancy could be due to the rather hydrophilic character of this protein, since a number of hydrophilic proteins have been observed to migrate more slowly than expected on SDS-PAGE gels (28).

To show that the DNA sufficient to encode the VirE2 protein does indeed

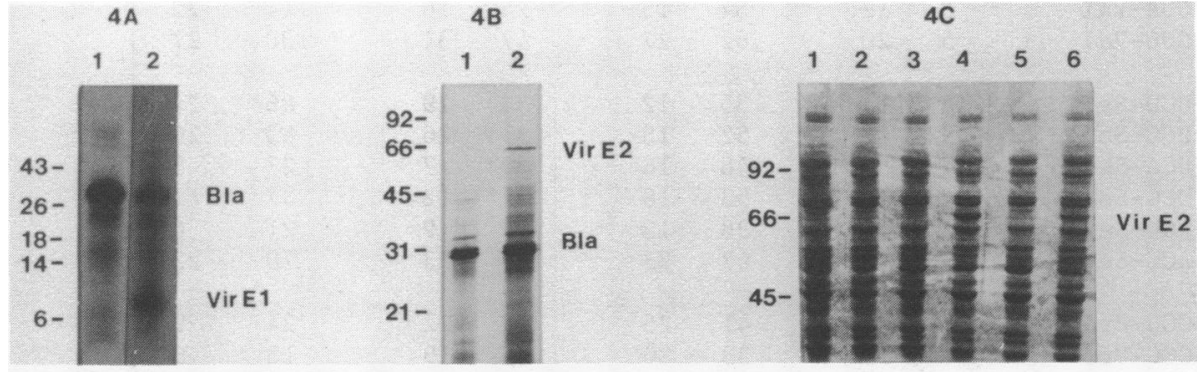

Figure 4: SDS-PAGE electrophoresis of the VirE1 and VirE2 proteins. Low molecular weight products of the vector pUC19 (Part 4A, lane 1) and of pSW108 (Part 4A, lane 2) were visualized using a 15\% phosphate-SDS-UREA gel. Higher molecular weight proteins coded by pUC19 (Part 4b, lane 1) and pSW108 (Part 4b, lane 2) were visualized using a $10 \%$ Trjs-SDS gel. In both gels, plasmidencoded proteins were radiolabelled with ${ }^{35} \mathrm{~S}-$ methionine in $\mathrm{E}$. coli maxicells. The native virE2 protein was also visualized in $\mathrm{E}$. coli among total cell protein (Part 4C) by creating a transcriptional fusion between the lac promoter and virE as described in Materials and Methods. Part C, lane 1: pUC19, -IPTG; lane 2: pUC19, +IPTG; lane 3: pSW153, -IPTG; lane 4: pSW153, +IPTG; lane 5: pSW154, -IPTG; lane 6: pSW154, +IPTG. 
correspond to the large ORF, we constructed two derivatives of pUC19 (pSW153 and pSW154) containing virE DNA shown in Fig. 1. In each of these plasmids, the first 6 codons of virEl have been replaced by the first 7 codons of the lacZ gene of pUC19. These plasmids therefore contain lacZ: :virEl transla-

Table 1. Codon usage analysis for the two virE genes, nine Agrobacterium vir genes, eight T-DNA genes, and $25 \mathrm{E}$. coli genes.

\begin{tabular}{|c|c|c|c|c|c|c|c|c|}
\hline & \multicolumn{2}{|c|}{$2 \underset{\text { girE }}{\text { genes }}$} & \multicolumn{2}{|c|}{9 vir } & \multicolumn{2}{|c|}{$\begin{array}{c}8 \text { T-DNA } \\
\text { genes }\end{array}$} & \multicolumn{2}{|c|}{25 genes } \\
\hline & total & $\%$ & total & $\%$ & total & $\%$ & total & $\%$ \\
\hline UUU-Phe & 12 & 57 & 77 & 60 & 59 & 50 & 104 & 44 \\
\hline UUC-Phe & 9 & 43 & 52 & 40 & 58 & 50 & 135 & 56 \\
\hline UUA-Leu & 3 & 6 & 28 & 7 & 23 & 9 & 36 & 6 \\
\hline UUG-Leu & 12 & 27 & 67 & 18 & 49 & 19 & 51 & 8 \\
\hline CUU-Leu & 6 & 13 & 84 & 22 & 53 & 21 & 54 & 9 \\
\hline CUC-Leu & 9 & 20 & 62 & 16 & 45 & 17 & 41 & 7 \\
\hline CUA-Leu & 3 & 7 & 42 & 16 & 27 & 10 & 11 & 2 \\
\hline CUG-Leu & 12 & 27 & 78 & 20 & 61 & 24 & 432 & 69 \\
\hline AUU-Ile & 11 & 38 & 93 & 43 & 61 & 38 & 151 & 37 \\
\hline AUC-Ile & 13 & 45 & 91 & 42 & 61 & 38 & 252 & 62 \\
\hline AUA-Ile & 5 & 17 & 33 & 15 & 38 & 24 & 2 & 1 \\
\hline AUG-Met & 16 & 100 & 73 & 100 & 55 & 100 & 189 & 100 \\
\hline GUU-Val & 8 & 32 & 77 & 34 & 51 & 33 & 182 & 38 \\
\hline GUC-Val & 9 & 36 & 56 & 24 & 32 & 21 & 62 & 13 \\
\hline GUA-Val & 3 & 12 & 34 & 15 & 24 & 16 & 111 & 23 \\
\hline GUG-Val & 5 & 20 & 62 & 27 & 47 & 31 & 130 & 27 \\
\hline UCU-Ser & 6 & 12 & 35 & 12 & 33 & 19 & 86 & 27 \\
\hline UCC-Ser & 9 & 18 & 52 & 18 & 35 & 20 & 83 & 26 \\
\hline UCA-Ser & 4 & 8 & 48 & 16 & 30 & 17 & 27 & 8 \\
\hline UCG-Ser & 8 & 16 & 53 & 18 & 22 & 12 & 37 & 11 \\
\hline AGU-Ser & 8 & 16 & 38 & 13 & 16 & 9 & 21 & 6 \\
\hline AGC-Ser & 15 & 30 & 67 & 23 & 41 & 23 & 70 & 22 \\
\hline CCU-Pro & 8 & 24 & 41 & 25 & 29 & 22 & 24 & 9 \\
\hline CCC-Pro & 4 & 12 & 33 & 20 & 25 & 19 & 16 & 6 \\
\hline CCA-Pro & 10 & 29 & 39 & 24 & 48 & 36 & 53 & 20 \\
\hline CCG-Pro & 12 & 35 & 52 & 32 & 32 & 24 & 174 & 65 \\
\hline ACU-Thr & 6 & 23 & 33 & 20 & 28 & 23 & 76 & 24 \\
\hline ACC-Thr & 10 & 38 & 57 & 35 & 30 & 25 & 162 & 51 \\
\hline ACA-Thr & 6 & 23 & 35 & 21 & 40 & 33 & 19 & 6 \\
\hline ACG-Thr & 4 & 15 & 40 & 24 & 23 & 19 & 63 & 20 \\
\hline GCU-Ala & 11 & 26 & 76 & 24 & 68 & 30 & 202 & 28 \\
\hline GCC-Ala & 9 & 21 & 80 & 25 & 55 & 24 & 136 & 19 \\
\hline GCA-Ala & 5 & 12 & 69 & 21 & 63 & 28 & 166 & 23 \\
\hline GCG-Ala & 17 & 40 & 97 & 30 & 42 & 18 & 221 & 30 \\
\hline
\end{tabular}


Table 1 (cont.)

\begin{tabular}{|c|c|c|c|c|c|c|c|c|}
\hline & \multicolumn{2}{|c|}{$2 \frac{\text { virE }}{\text { genes }}$} & \multicolumn{2}{|c|}{9 vir } & \multicolumn{2}{|c|}{$\begin{array}{l}8 \text { T-DNA } \\
\text { genes }\end{array}$} & \multicolumn{2}{|c|}{25 genes } \\
\hline & total & $\%$ & total & $\%$ & total & $\%$ & total & $\%$ \\
\hline UAU-Tyr & 10 & 47 & 46 & 59 & 55 & 63 & 69 & 41 \\
\hline UAC-Tyr & 11 & 52 & 32 & 41 & 32 & 37 & 101 & 59 \\
\hline UAA-Ter & 0 & 0 & 1 & 11 & 4 & 50 & 22 & 88 \\
\hline UAG-Ter & 0 & 0 & 3 & 33 & 3 & 38 & 1 & 4 \\
\hline UGA-Ter & 2 & 100 & 5 & 56 & 1 & 13 & 2 & 8 \\
\hline $\mathrm{CAU}-\mathrm{His}$ & 8 & 50 & 39 & 49 & 33 & 65 & 42 & 39 \\
\hline $\mathrm{CAC}-\mathrm{His}$ & 8 & 50 & 40 & 51 & 18 & 35 & 66 & 61 \\
\hline $\mathrm{CAA}-\mathrm{Gln}$ & 14 & 52 & 74 & 51 & 55 & 56 & 75 & 27 \\
\hline CAG-Gln & 13 & 48 & 72 & 49 & 44 & 44 & 207 & 73 \\
\hline $\mathrm{AAU}-\mathrm{Asn}$ & 20 & 61 & 71 & 55 & 57 & 50 & 57 & 24 \\
\hline AAC-Asn & 13 & 39 & 58 & 45 & 56 & 50 & 179 & 76 \\
\hline AAA-Lys & 15 & 48 & 80 & 53 & 57 & 56 & 296 & 77 \\
\hline AAG-Lys & 16 & 52 & 70 & 47 & 45 & 44 & 90 & 23 \\
\hline GAU-Asp & 17 & 45 & 105 & 52 & 78 & 55 & 175 & 51 \\
\hline GAC-Asp & 21 & 55 & 97 & 48 & 65 & 45 & 168 & 49 \\
\hline GAA-Glu & 25 & 53 & 125 & 51 & 79 & 56 & 328 & 73 \\
\hline GAG-Glu & 22 & 47 & 121 & 49 & 61 & 44 & 119 & 27 \\
\hline UGU-Cys & 0 & 0 & 11 & 38 & 18 & 35 & 21 & 42 \\
\hline UGC-Cys & 4 & 100 & 18 & 62 & 34 & 65 & 29 & 58 \\
\hline UGG-Trp & 6 & 100 & 27 & 100 & 33 & 100 & 48 & 100 \\
\hline CGU-Arg & 9 & 19 & 57 & 19 & 16 & 11 & 201 & 58 \\
\hline CGC-Arg & 11 & 23 & 80 & 27 & 28 & 19 & 121 & 35 \\
\hline CGA-Arg & 4 & 9 & 49 & 16 & 23 & 15 & 8 & 2 \\
\hline CGG-Arg & 10 & 21 & 11 & 17 & 32 & 21 & 11 & 3 \\
\hline AGA-Arg & 6 & 13 & 30 & 10 & 22 & 15 & 4 & 1 \\
\hline AGG-Arg & 7 & 15 & 31 & 10 & 29 & 19 & 1 & 0.25 \\
\hline GGU-Gly & 10 & 25 & 53 & 26 & 52 & 27 & 231 & 48 \\
\hline GGC-Gly & 17 & 43 & 67 & 33 & 52 & 27 & 197 & 41 \\
\hline GGA-Gly & 7 & 18 & 44 & 21 & 58 & 30 & 22 & 5 \\
\hline GGG-G1y & 6 & 15 & 42 & 20 & 33 & 17 & 33 & 7 \\
\hline
\end{tabular}

tional fusions and transcriptional fusions between the lac promoter and the native v1rE2 gene. pSW154 contains T1 plasmid DNA only 39 bp downstream from the end of the virE2 ORF. Fig. 4c shows that pSW154 contains a full length VirE2 protein, indicating that the entire gene must 1 ie between the SphI and SmaI sites shown in Fig. 1. Neither plasmid synthesized detectable levels of 
the 1acZ: :virEl translational fusion protein either among whole cell proteins using Commassie blue staining or by radiolabelling of plasmid-coded protein using a maxicell strain (data not shown). This may have been due to instability of the fusion protein.

Codon Usage Analysis

We have analyzed the frequency at which all 64 codons are utilized, comparing, $i)$ the two virE proteins, ii) all nine sequenced Agrobacterium vir genes, (virG, ref. 9; virC1 and virC2, ref. 6; virD1 and virD2, ref. 11 ; and the virA genes of plasmids pTiA6 and pTiAg162, ref. 29), iii) eight T-DNA genes (all of which are expressed in plants, ref. 30), and iv) a published compilation of $25 \mathrm{E}$. coli non-regulatory proteins (31). As shown in Table 1 , the two virE genes show generally similar codon usage to that of other vir genes and to T-DNA genes. This pattern of codon usage is quite different that found in E. coli, however, where certain codons are used very infrequently (for example, the isoleucine AUA codon or the arginine AGG codon) while others are used very frequently (for example, the leucine CUG codon or the arginine CGU codon). In contrast, Agrobacterium vir and T-DNA genes utilize all codons with a far more uniform frequency. For example, none of the six leucine codons is used more than $23 \%$ of the time, and similarly, the six arginine codons are utilized between $10 \%$ and $28 \%$ of the time. This generalization holds true for all other codons (Table 1).

\section{DISCUSSION}

The virE locus is essential for the efficient formation of crown gall tumors by Agrobacterium on susceptible host plants. In the present study, we have determined the nucleotide sequence of this operon, and visualized two proteins in maxicells which correspond in size to the two proteins predicted by the DNA sequence. Transposon insertions in either gene cause a strongly attenuated virulence. These data indicate that VirE2 is necessary for efficient virulence. On the other hand, we cannot assume that VirEl also is required for virulence since insertions in this gene will likely be polar upon virE2 and this alone could account for the avirulent phenotype. Further studies are therefore required to determine whether VirEl is required for virulence. The Lipman and Pearson FASTP program (32) was used to search the PIR protein database of the National Biomedical Research Foundation (Release 9.0, May, 1986; 3557 sequences) for proteins homologous to the virE1 and virE2 products. No homologous proteins were found.

The ability of virE mutants to be complemented by helper strains may be 
similar to several other recently reported phenomena. Female strains of Streptococcus which are unable to synthesize sex pheromones can be complemented by pheromone-proficient strains (33). Similarly, Rhizobium exopolysaccharide mutants, which normally form ineffective nodules, can be rescued by exopolysaccharide-proficient helper strains (A. Hirsch and J. Leigh, personal communication). Perhaps most intriguing, a conjugal transfer system has been reported to have similar properties (34). In that study, strains having a mutation in the traC locus could be complemented by helper strains. Complementation of traC mutants was observed only if the helper strain expressed, in addition to traC, all seven genes necessary for synthesis of sex pili. It was hypothesized that the helper strains were able to donate sex pili to the strain containing the traC mutation and that the mutant strain could assemble functional pili utilizing exogenously supplied pilin protein. However, whether or not traC codes for a pilin protein, there are at least three reasons to suspect that virE may not: 1 ) neither virEl nor virE2 shows detectable amino acid homology to any known pilin. ii) pilin proteins contain amino terminal signal sequences (34), while virE1 and virE2 lack such sequences. iii) if virEl or virE2 coded for any structure similar to a sex pilus, then then one might imagine that virE mutants would be deficient in binding plant cells. This is not the case, since Ti-plasmid deficient strains bind plant cells as well as strains containing the plasmid (36).

Nevertheless, it seems possible that transcellular complementation of virE mutations may involve a mechanism analogous (if not homologous) to one or more of the systems described above. In at least three cases, including virE, complementation was observed only if the helper strains expressed a number of genes in addition to the ones they were complementing. Also, in at least two cases, the complemented gene coded for a product which was itself secreted or which synthesized a secreted product. It seems a plausible hypothesis, therefore, that either VirE1 or VirE2, or both, may likewise be extracellularly localized or that they may synthesize an exported product. We are currently attempting to overproduce these proteins in order to raise antibodies against them, which will be used to determine the localization of these two gene products during infection.

\section{ACKNOWLEDGEMENTS}

We thank J. Champoux for providing his unpublished PROTANA program for hydrophilicity analysis, and P. Totten and A. Das for supplying bacterial 
mutants and plasmids prior to publication. This work was supported by NIH grant 5 ROI GM 32618-14, and National Science Foundation grant DMB-8315826. S.C.W. was supported by a Damon Runyon-Walter Winchell Cancer Fund Fellowship, DRG-800.

*Present address: Signal UOP Research Center, 50 UOP Plaza, Des Plaines, IL 60016, USA

\section{REFERENCES}

1. Nester, E.W., Gordon, M.P., Amasino, R.M. and M.F. Yanofsky. (1984). Ann. Rev. Plant Physiol. 35:387-413

2. Garfinkel, D.J. and Nester, E.W. (1980). J. Bacteriol. 144:732-743.

3. Klee H.J., White, F.F., Iyer, V.N., Gordon, M.P. and Nester E.W. (1983). J. Bacteriol. 153:878-883.

4. Douglas C.J. Staneloni R.J., Rubin R.A., and Nester, E.W. (1985). J. Bacteriol. 161:850-860.

5. Stachel, S. E. and Nester, E.W., (1986). EMBO J. 5:1445-1454.

6. Yanofsky, M.F. and Nester, E.W. (1986). J. Bacteriol. 168:244-250.

7. Horsch, R.B., Klee, H.J. Stachel, S., Winans, S.C., Nester, E.W., Rogers, S.G., and Fraley R.T. (1986). Proc. Nat1. Acad. Sci. 83:2571-2575.

8. Stache1, S.E. and Zambryski, P.C. (1986). Cel1 46:325- $\overline{33} 3$.

9. Winans, S.C., Ebert, P.R., Stache1, S.E., Gordon, M.P. and Nester, E.W. (1986). Proc. Nat1. Acad. Sci. 83:8278-8282.

10. Alt-Moerbe, J., Rak. B., and J. Schroder. (1986). EMBO J. 5: 1129-1135.

11. Yanofsky, M.F., Porter, S.G., Young, C., Albright, L.M., Gordon, M.P., and Nester, E.W., Ce11 47:471-477.

12. Otten, L., DeGreve, H., Leemans, J., Hain, R., Hooykaas, P. and Sche11, J. (1984). Mo1. Gen. Genet. 195:159-163.

13. Gardner, R.C. and Knauf, V.C. (1986). Science 231:725-727.

14. Birnboim, H.C. and Doly, J. (1979). Nuc1. Acids Res. 7:1513-1523.

15. Sanger, F., Nicklen, S., and Coulson, A.R. (1977). Proc. Natl. Acad. Sci. USA 74:5463-5467.

16. Biggin, H.D., Gibson, T.J. and Hong, G.F. (1983). Proc. Natl. Acad. Sci. USA 80:3963-3965.

17. Guo, L. -H. and Wu, R. (1983). Methods Enzymol. 100:60-96.

18. Dale, R.M.K., McClure B.A., and Houchins, J.P. (1985). Plasmid 13: $31-40$.

19. Sancar, A., Warton, R.P., Seltzer, S., Kacinski, B.M., Clarke, N.D. and Rupp, W.D. (1981). J. Mol. Biol. 45-62.

20. Laemmli, U.K. (1970). Nature 277:680-685.

21. Anon. (1985). Focus 6:5.

22. Stachel, S.E., An, G., Flores, C., and Nester, E.W. (1985a). EMBO J. 4:891-898.

23. Shine, J. and Dalgarno, L. (1975). Nature 254:34-38.

24. Das, A., Stachel, S., Ebert, P., Allenza, P., Montoya, A., and Nester, E. (1986). Nuc1. Acids Res. 14:1355-1364.

25. Stachel, S.E. Nester, E.W., and Zambryski, P.C. (1986b). Proc. Natl. Acad. Sci. USA 83:379-383.

26. Hopp, T.P. and Wood, K.R. (1981). Proc. Natl. Acad. Sci. USA 78:3824-3838.

27. Inouye, S., Soberon, X., Franceschini, T., Nakamura K., Itakura, K., and Inouye, M. (1982). Proc. Nat1. Acad. Sci. 79:3438-3441.

28. Merrick, M.J. and Gibbins, J.R., (1985). Nucl. Acids Res. 13:7607-7620. 
29. Leroux, B., Yanof sky, M.F., Winans, S.C., Ward, J., Zeigler, S.J., and Nester, E.W., EMBO J. in press.

30. Gielen, J., De Beuckeleer, M., Seurinck, J., Deboeck, F., De Greve, H., Lemmers, M., Van Montagu, M., and Sche11, J. (1984). EMBO J. 3:835-846.

31. Konigsberg, W., and Godson, G.N. (1983). Proc. Nat1. Acad. Sci. USA 80:687-691.

32. Lipman, D.J. and Pearson, W.R. (1985). Science 227:1435-1441.

33. Clewel1, D.B., An, F.Y., White, B.A., and Gawron-Burke, C. (1985). J. Bacteriol. 162:1212-1220.

34. Winans, S.C., and Walker, G.C. (1985). J. Bacteriol. 161:402-410.

35. Johnson, K., Parker, M.L., and Lory, S. J. Biol. Chem. in press.

36. Douglas, C.J., Halperin W., and Nester, E.W. (1982). J. Bacteriol. 152: $1265-1275$. 